This item was submitted to Loughborough's Research Repository by the author.

Items in Figshare are protected by copyright, with all rights reserved, unless otherwise indicated.

\title{
Information mapping between a feature-based design system and an integrated process planning system
}

PLEASE CITE THE PUBLISHED VERSION

PUBLISHER

(C) University of Manchester Institute of Science and Technology in association with The Macmillan Press

\section{VERSION}

AM (Accepted Manuscript)

\section{LICENCE}

CC BY-NC-ND 4.0

\section{REPOSITORY RECORD}

Gao, James, and Keith Case. 2019. "Information Mapping Between a Feature-based Design System and an Integrated Process Planning System". figshare. https://hdl.handle.net/2134/14281. 
This item was submitted to Loughborough's Institutional Repository (https://dspace.lboro.ac.uk/) by the author and is made available under the following Creative Commons Licence conditions.

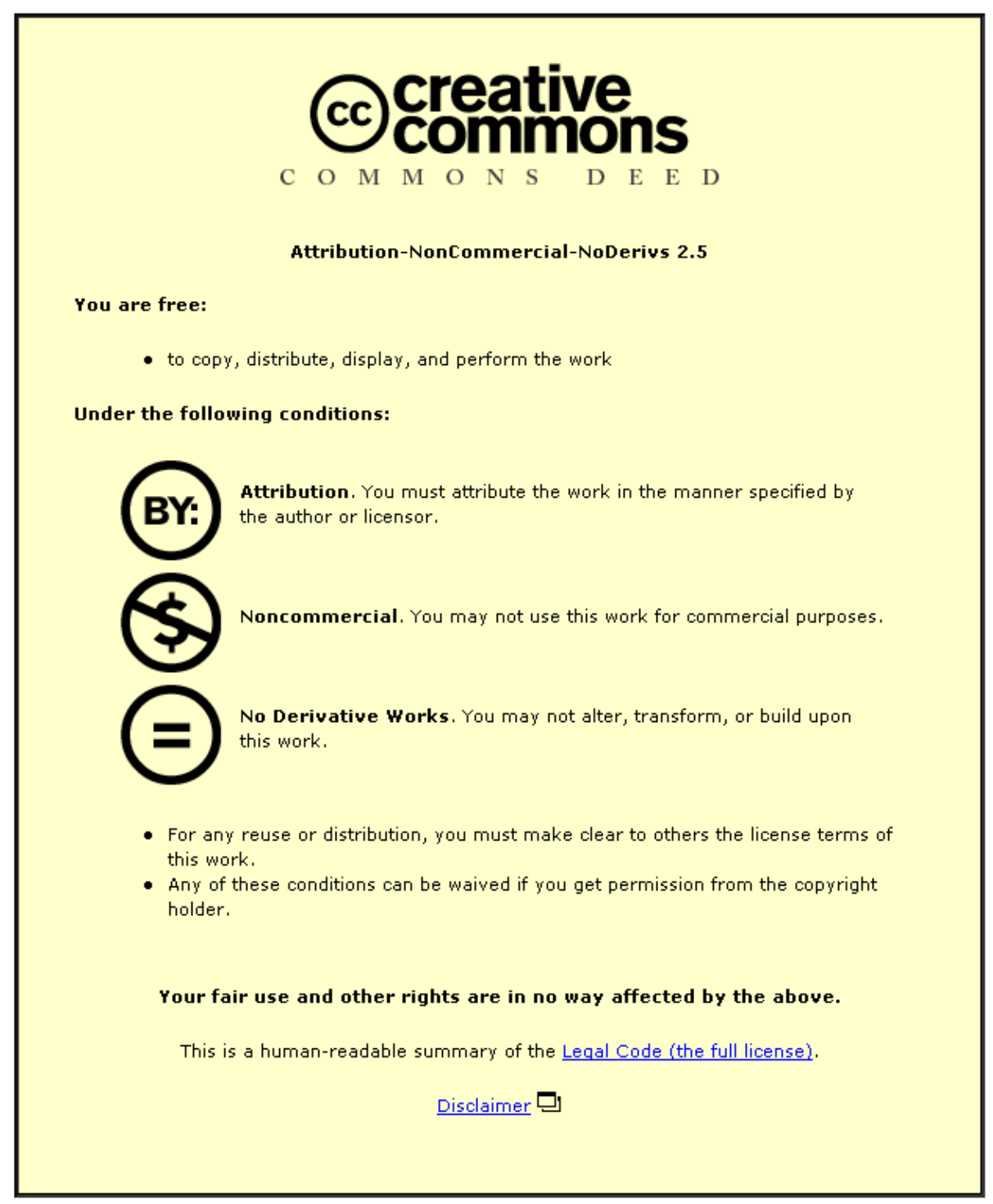

For the full text of this licence, please go to: http://creativecommons.org/licenses/by-nc-nd/2.5/ 


\title{
INFORMATION MAPPING BETWEEN A FEATURE-BASED DESIGN SYSTEM AND AN INTEGRATED PROCESS PLANNING SYSTEM
}

\author{
J.X. GAO AND K. CASE \\ Loughborough University of Technology Leicestershire, LE11 3TU
}

\begin{abstract}
This paper introduces a prototype feature-based design system and a mechanism for mapping its data to an integrated knowledge-based process planning system. The information includes the primary feature data directly from the design front-end, a boundary representation (Brep) model of the feature geometry, processed manufacturing feature data and re-formatted data for the planning system. The difference between the component representations at the design stage and at the process planning stage are analysed, and the difficulties and problems with each mapping activity are also discussed. An example is given to demonstrate the main tasks of the data mapping process between the integrated Computer-Aided Design (CAD) and Computer-Aided Manufacture (CAM) systems.
\end{abstract}

\section{Introduction}

Most contemporary Computer Aided Design (CAD) tools, including two dimensional drafting systems, three dimensional wireframe, surface and solid modellers, are developed for representing the geometry of components. However, information about component features (e.g. holes, pockets, slots and steps) and their relationships, tolerances, surface finish and so on is missing in the geometric data models (Case and Gao, 1993). This information is essential for manufacturing planning processes and therefore, the representation of features at the design stage is significant for the integration of CAD and CAM (Computer Aided Manufacture) systems. Although great efforts have been made in the development of feature-based CAD systems (Gao and Case, 1992, Dixon, 1988, Shah and Rogers, 1990), it is still not possible for CAD systems to store all the detailed technical information required for a variety of different applications without losing its generality as a design system. Therefore, information mapping (conversion) between design systems and the related application systems is inevitable (Shah et al 1988).

This paper introduces a prototype feature based design system, LUT-FBDS (Loughborough University of Technology Feature Based Design System), with an emphasis on the information mapping mechanism between the design system and an integrated process planning system. The design system contains a primary feature representation and a boundary representation (Brep) model of a component. The two preliminary data models are processed into a more detailed data model containing all the required data for planning the manufacturing processes of the component (Gao and Case, 1991). This is the main mapping process that is described in this paper. Other processors include one which reformats the data into frames suitable for a knowledge-based planning system which is being developed in parallel (Gindy and Huang, 1992). The problems and difficulties experienced in providing each of the data conversions are discussed in the following sections.

\section{Design Features versus Manufacturing Features}

Features are application dependent (Butterfield et al 1985). Design engineers treat features as functional features to fulfill functional requirements. Functional features may also be called design features. However, process planners view features as manufacturing features. What concerns the process planners is how the features may be machined and whether enough data is available for them to make the right decision. This issue is discussed in more detail below.

\subsection{Functional information about features}

At the design stage, parts are specified to satisfy specific functional requirements. Figure 1 shows the functional features on a bore and keyway component (from GEC Alsthom Large Machines $L t d$.). The keyway and bore features are used for power transfer and the pattern of through holes are used for fixing the component. The specified surface finish of the internal face of the bore and its perpendicularity tolerance to face $A$ are required to assure the component's performance. Tolerances and surface finish are called 
functional attributes. Other information (attributes) which affect the component's functional performance include material specifications, such as material type, hardness and strength.

In addition to the data about single features, relational information between features is also of functional importance. Examples are four holes at each corner of a rectangular plate (figure 2a) and two stepped holes (figure 2b). The former may be called a pattern of holes which together satisfy a functional requirement (such as locating and clamping the plate); The latter is a counter-

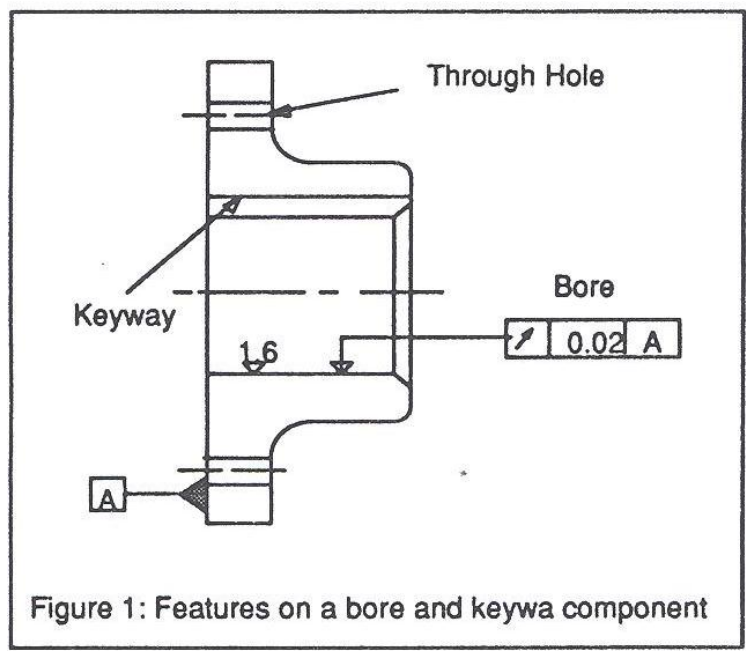

bored hole and both are defined as compound features. Dimensional tolerances between two features (see Figure 2a) are also relational information that should be represented in the design system.

In summary, the functional information about component features includes feature geometry, tolerances, surface finish, relationships (compound features) and material specifications, all of which should be represented in CAD data models.

\subsection{Manufacturing Data and Features}

Feature information in a CAM system (e.g. a computer aided process planning system) includes most of the design data stored in a CAD system. For instance, feature geometry, tolerances, surface finish and material specifications are all necessary for NC (Numerical Control) code generation, cutting tool selection and manufacturing process determination. This data can be transferred directly from the design system to the planning system without further processing.

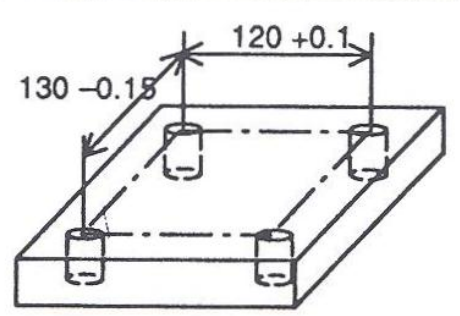

(a) Pattern of Holes

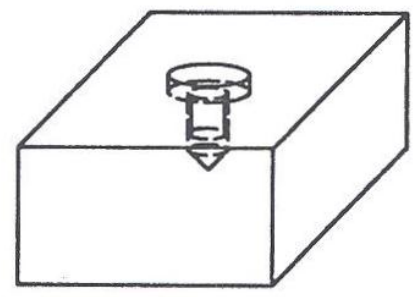

(b) Counter-bored hole

Figure 2: Examples of Compound features

The relational information/compound features defined as part of the functional design may also have great significance within manufacturing planning systems. However, process planners might interpret the information differently. For example, the compound feature shown in Figure 2 a may still be treated as pattern holes by a planning system since individual holes may be machined by a group of similar operations (say drilling and reaming) with minimum tool changing. Counter-bored holes of the type shown in Figure $2 \mathrm{~b}$ may be machined by a fixed sequence of machining operations in a specific company by merely changing the tool sizes. Therefore, relationships and compound features defined in the design system need to be translated to give manufacturing meaning in the planning system.

There is some information which is important to process planning, but which is missing in the design system (or not considered by design engineers). For example, a feature is defined as a volume enveloped by a set of faces (Gindy 1989), and some of these enveloping faces do not exist in the geometric model. These imaginary faces are important since they may be used in defining directions from which features may be accessed by cutting tools. Figure $3 a$ shows a slot that can be accessed from three External Access Directions (EADs), where an 
EAD is usually the normal to an imaginary face. Figure $3 b$ shows two blind holes located on the bottom face of a step (Note that blind holes are classified as pockets with round profiles in our feature taxonomy). From the process planning point of view the holes may have to be machined after the step. If the holes are to be machined before the step, the dimensions of the step must be taken into account when selecting cutting processes for the holes, since the holes may become thin deep blind holes of which special cares must be taken. This type of relationship is called parent-child relationship. The holes are called the children of the step, and the step is called the parent of the holes. The face of the parent feature and the face of the child feature which are coincident are called the parent face and the child face respectively. The normal vectors of the faces of the block are also important to the determination of set ups and clamping strategy. This information is implicitly stored in the geometric models, but is required

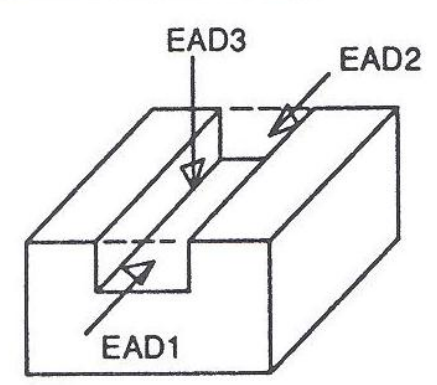

(a)

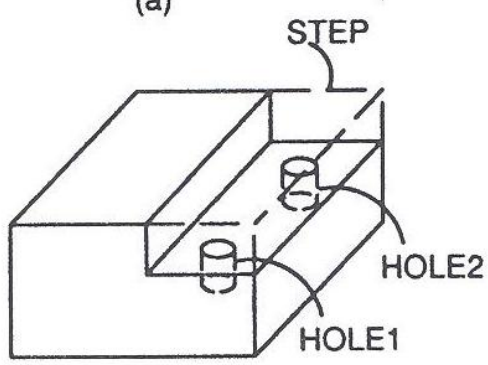

(b)

Figure 3: Feature Information Required by Process Planning

explicitly in the manufacturing data model.

In summary, most of the feature data in the design system can be directly transferred to the manufacturing data model, e.g. material specifications, geometry, tolerances and surface finish. Some relational data such as compound features defined in the design system has to be translated into the manufacturing data model. There is some information which is important to manufacturing planning, but is missing or only implicitly stored in the geometric model (for example external access directions, imaginary faces, parent-child relationships and normal vectors of the faces of the stock material).

\subsection{Data Mapping between Design and Planning Systems}

From the above discussion it can be seen that the feature data model in the design system cannot be used directly for application systems. Data mapping between design systems and process planning systems is necessary regardless of the sophistication of the design system (whether it be geometric or featurebased). The basic tasks of the mapping process are to:

(a) derive implicit data (such as normals of block faces) by interrogating the design system.

(b) to add information missing in the design system, e.g. imaginary faces and external access directions of features.

(c) reason about the parent-child relationships between features and to determine parent and child faces.

(d) translate functional relationships/compound features defined in the design system into relationships/compound features of manufacturing significance.

(e) re-organize the data structure for process planning systems.

\section{The Implemented Feature-Based Design System}

Most CAD systems are used for modelling component geometry, and the feature information (dimensions and functional attributes) which is essential for process planning is not represented. This has been the main obstacle to the integration of the CAD systems with manufacturing planning systems. To overcome this problem, a design by features user interface to a solid modeller (Pafec Imaginer) has been developed to allow designers to generate components using feature primitives and to store attributes in a feature based data structure which is separate from, but associated with the 


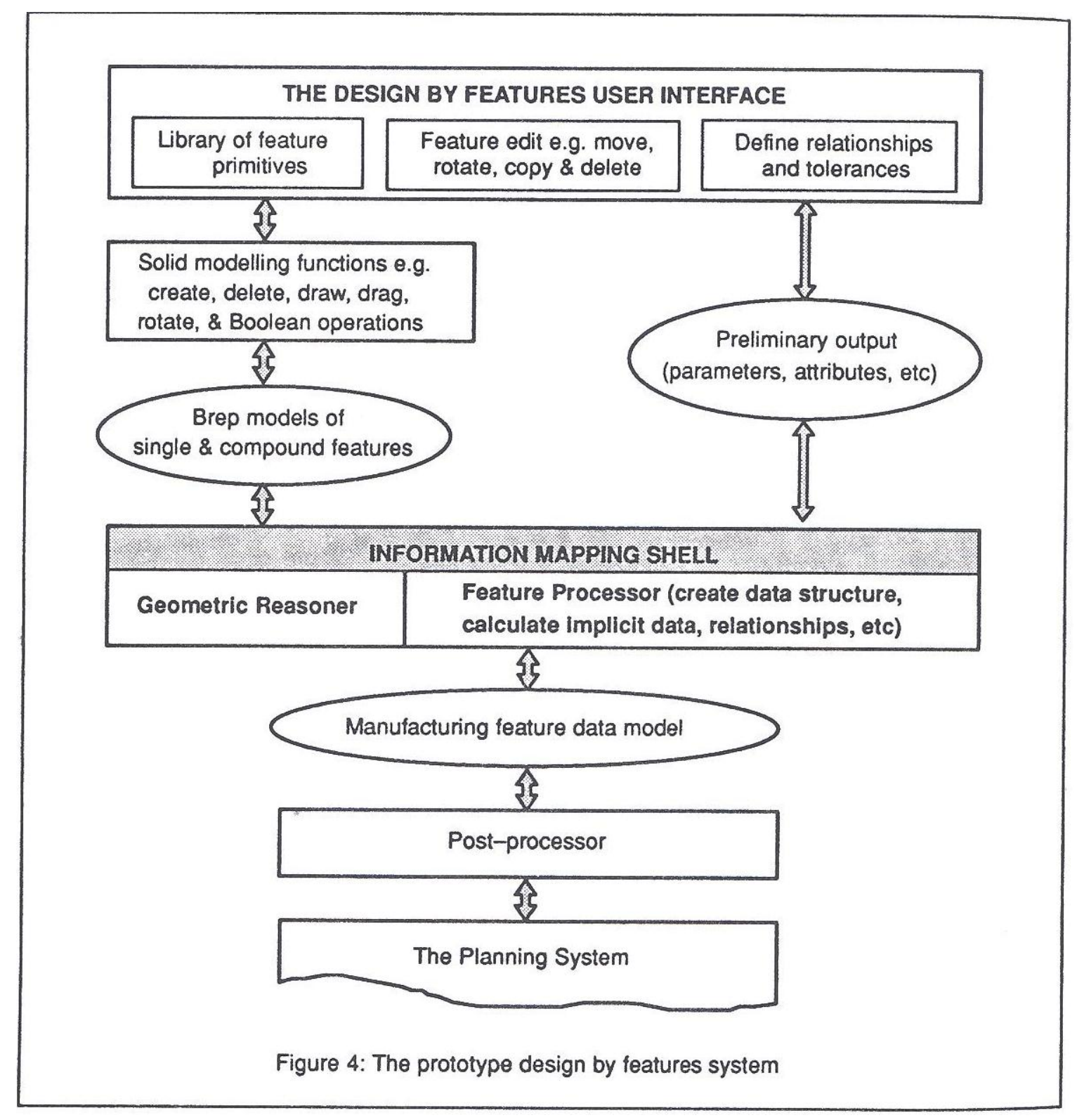

database of the geometric modeller. The structure of the system is shown in Figure 4:

The system consists of a design by features user interface, a solid modeller (Pafec Imaginer), a feature processor/geometric reasoner and a post-processor. The design by features interface allows designers to create feature instances by provision of parameters for feature primitives; to perform feature edit operations, such as move, rotate and delete; and to define feature relationships, such as compound features, tolerances and parent-child relationships. The interface is written in Horses (Pafec 1991), which is a User Interface Management System (UIMS) supplied by Pafec Limited.
The feature primitives currently available in the library are illustrated in Figure 5. They are classified into bosses, pockets, holes, through slots, non-through slots, notches, steps and compound features. Each feature class has a number of profile shapes associated with it. Once a feature is created through the design by features interface, a boundary representation (Brep) model is generated by the solid modeller and stored in its database. At the same time, information about the feature such as its dimensional and positional parameters, tolerances and surface finish is output into a preliminary output file. This temporary file is further processed by the feature processor into a data model which contains all the manufacturing 


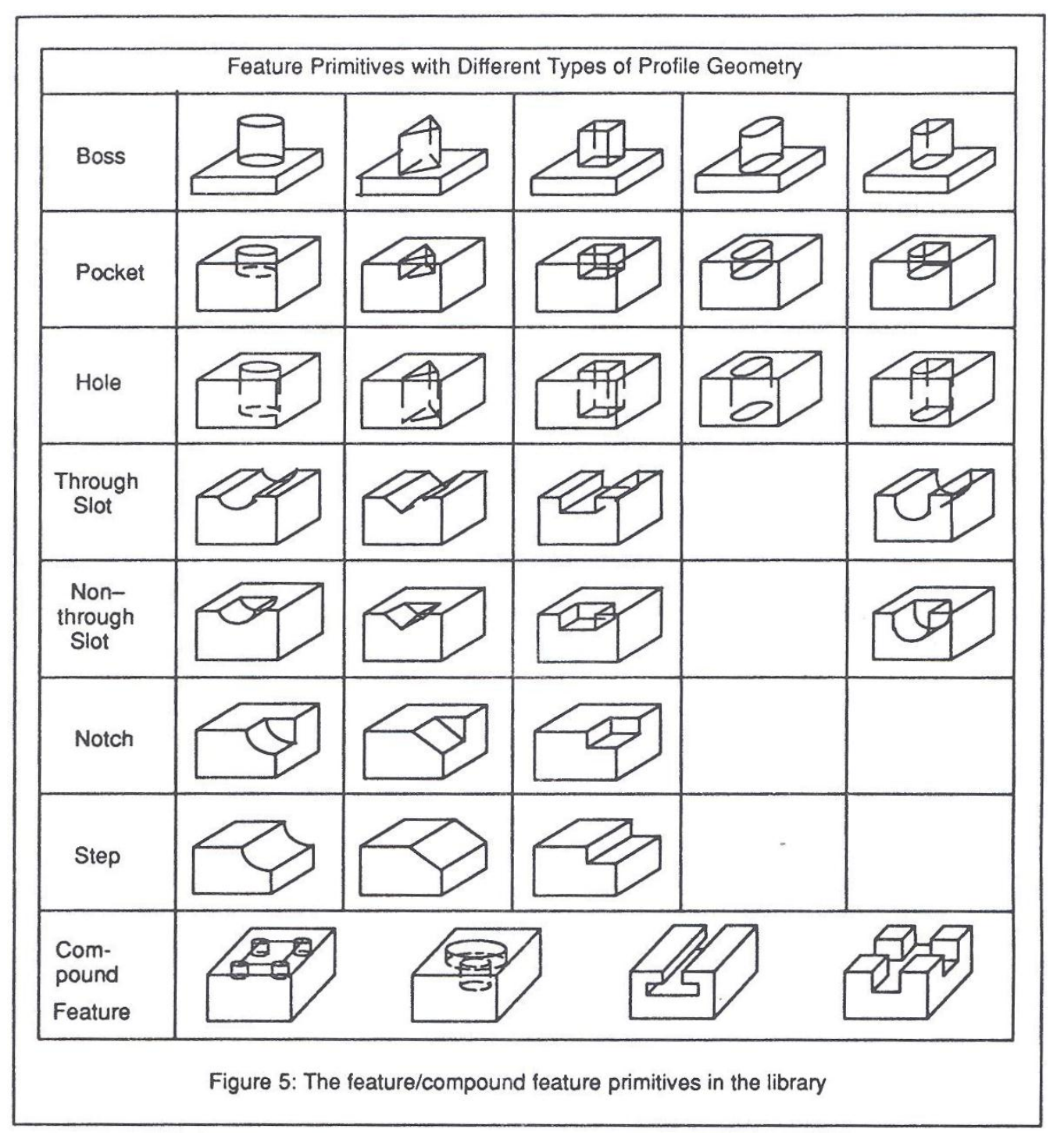

data relating to components as described in section 2.2. The Brep data model contains detailed geometric information about the components from which some missing geometric information in the manufacturing data model can be obtained by interrogating the Brep model through the geometric reasoner.

Both the feature processor and the geometric reasoner are undertaking the information mapping tasks listed in section 2.3. The postprocessor reads the manufacturing feature data and reformats it into a file which can be read by the knowledge-based planning system and stored in the planning database. The difference between the feature data before and after the mapping process can be seen more clearly through the illustrative example in the next section.

\section{An Example}

Figure 6 shows an example component that includes a compound feature (a pattern of through holes), a top pocket and a through hole at the bottom of the pocket. The names of the features are pattern h1, pattern h2, pattern h3, pattern_h4, top_pock and bot_hole respectively. The tolerances between the pattern holes are given as +0.1 and -0.15 respectively. The overall dimensions of the component are $(100,140,40)$. The information is divided into component level and feature level. The component level information contains general specifications of the component and relational data about different features, such as tolerances, compound features and parent-child relationships. Figure 7 shows the component level information for the example component. In fact, component level information can be directly 


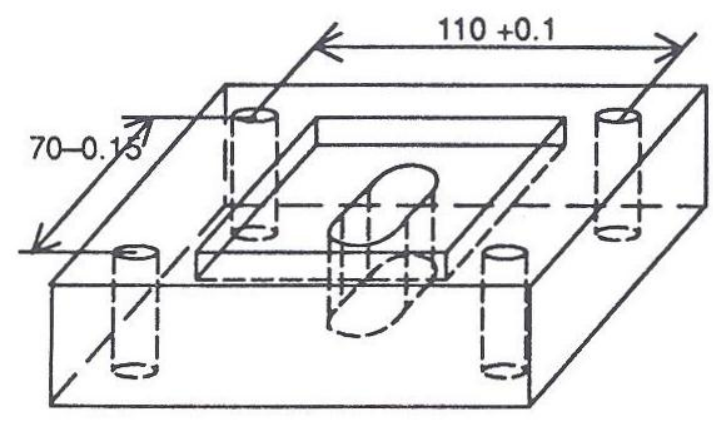

Figure 6: The example component

transferred to the manufacturing data model without processing. Therefore, this piece of data remains unchanged after the mapping process.

Feature level information contains data about individual features. This will include items such as feature classes, parameters, attributes, locations, orientations and information associated with faces. Figure 8 shows feature level information before data mapping and Figure 9 shows the feature data after the data mapping process. (Since the feature level data for pattern_h2, pattern_h3 and pattern_h4 is similar to that for pattern_h1, it is omitted from the figures). By comparing the two figures the following points can be seen:

(a) The data for each primitive feature in figure 8 is shown separately. This is easier for communication with the design front end, but it may make it difficult for the application software to search for data about a specific feature. In contrast the processed data about each feature (figure 9) is grouped together so that it is easier for application programs to access all the data about a single feature.

(b) More face information can be found in figure 9 , e.g. the normal vectors, face type (real or imaginary) and parent faces. Each imaginary face has a parent face and its default is one of the block faces. When a feature is a child of another feature (except the block), at least one parent face of the child feature is a real face of the parent feature (see the bottom hole in figure 9).

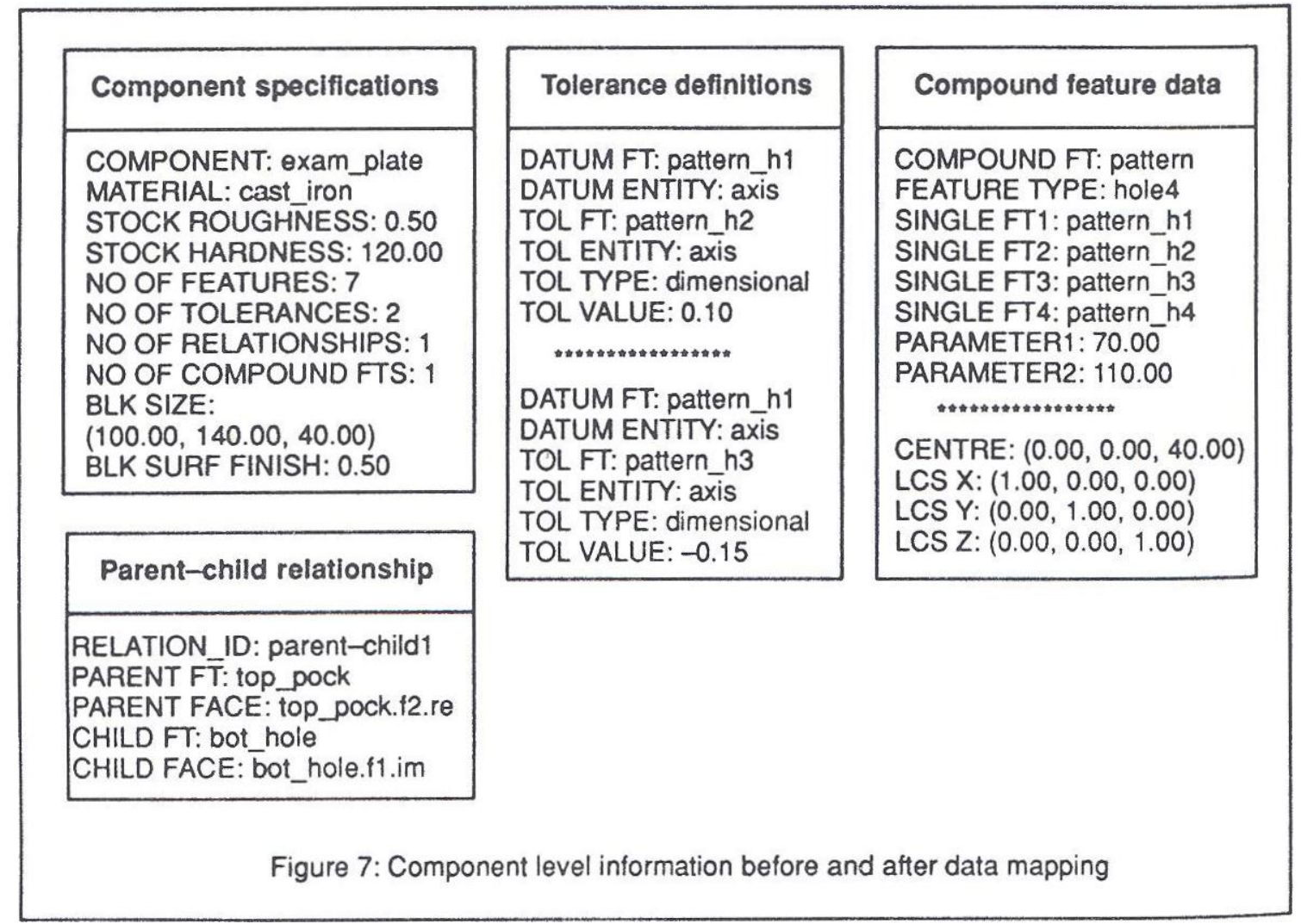




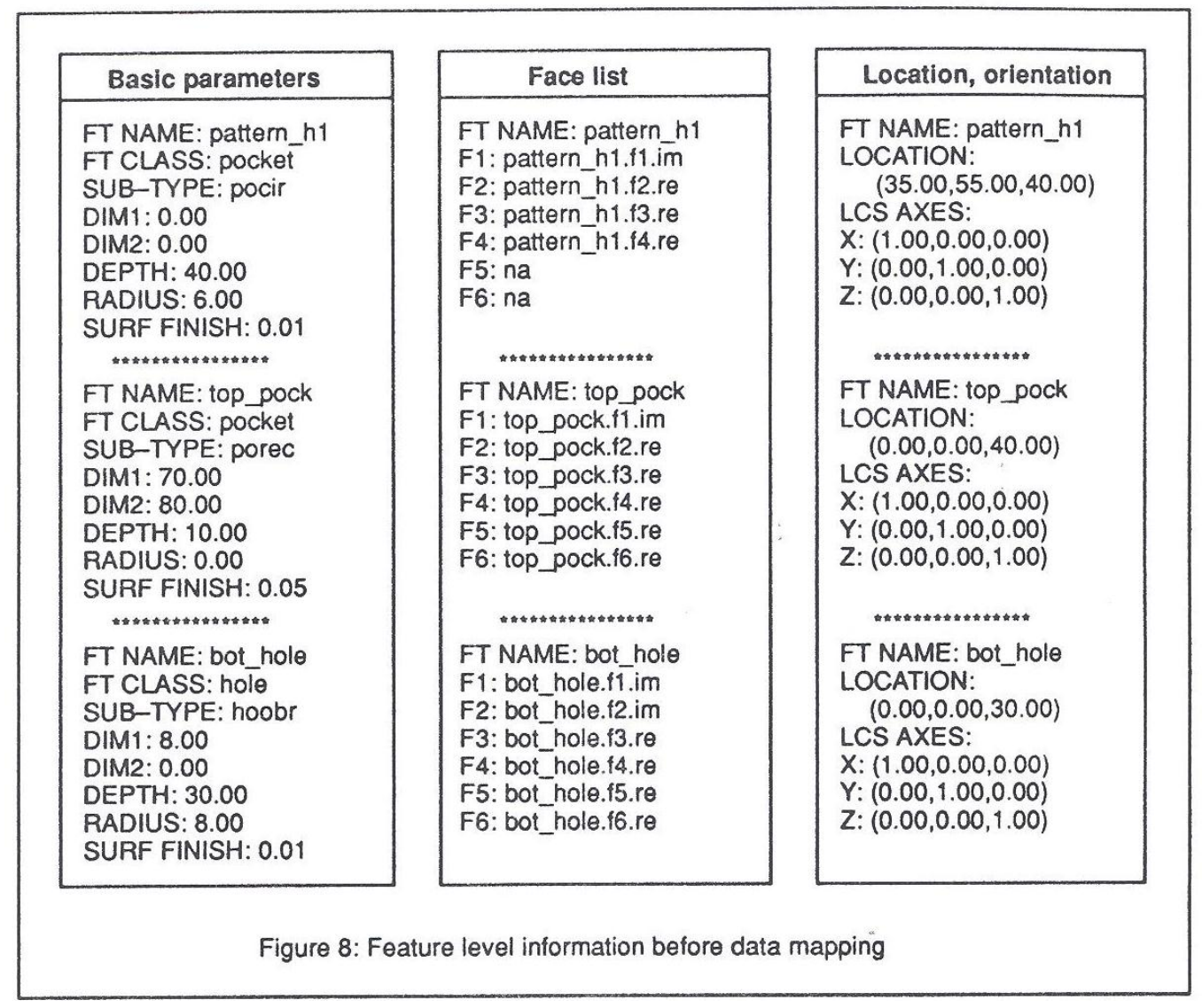

(c) Basic feature parameters, attributes, locations and orientations are unchanged after the mapping process.

(d) Compound features can be defined as primitives or relationships through the design front end. However, in the manufacturing data model, they are represented as relationships between individual features (see pattern holes).

In summary, the above analysis has shown that the implemented feature mapping shell can fulfill the tasks listed in section 2.3.

\section{Conclusions}

One of the main difficulties with the integration of Computer Aided Design systems and Computer Aided Manufacture systems has been the information conversion/mapping between the design data models and the manufacturing data models. In both data models, the representation of parts should be feature based. This paper has introduced a prototype feature-based design system, which is an improvement on conventional geometric modelling systems towards CAD/CAM integration. However, even with feature-based design facilities, information mapping between design data and manufacturing data is still inevitable, since features defined in the design systems are functional features and much of the information required in the manufacturing data models is missing in the design data models. The basic tasks of information mapping have been identified and tested during the implementation of the prototype system, which are listed in section 2.3 and repeated below:

(a) to derive implicit data (such as normals of block faces) by interrogating the design system.

(b) to add information missing in the design system, e.g. imaginary faces and external access directions of features.

(c) to reason about the parent-child relationships between features and to determine parent and child faces.

(d) to translate functional relationships/ compound features defined in the design system into relationships/compound features of manufacturing significance.

(e) to re-organize the data structure for process planning systems. 


\begin{tabular}{|c|c|c|}
\hline Pattern hole1 data & Top pocket data & Bottom hole data \\
\hline $\begin{array}{l}\text { FT NAME: pattern_h1 } \\
\text { FT CLASS: pocket } \\
\text { SUB-TYPE: pocir } \\
\text { OF COMP_FT: pattern } \\
\text { DIM1: 0.00 } \\
\text { DIM2: } 0.00 \\
\text { DEPTH: } 40.00 \\
\text { RADIUS: } 6.00 \\
\text { SURF FINISH: } 0.01 \\
\text { LOC:(35.00,55.00,40.00) } \\
\text { X: }(1.00,0.00,0.00) \\
\text { Y: (0.00,1.00,0.00) } \\
\text { Z: (0.00,0.00,1.00) } \\
\text { FACE: pattern_h1.f1.im } \\
\text { TYPE: i } \\
\text { PARENT: blk.f1.bl } \\
\text { NORM: }(0.00,0.00,1.00) \\
\text { FACE: pattern_h1.f2.re } \\
\text { TYPE: } r \\
\text { PARENT: } \\
\text { NORM: }(0.00,0.00,-1.00) \\
\text { FACE: pattern_h1.f3.re } \\
\text { TYPE: } r \\
\text { PARENT: } \\
\text { NORM: }(0.00,0.00,0.00) \\
\text { FACE: pattern_h1. }\{4 . r e \\
\text { TYPE: } r \\
\text { PARENT: } \\
\text { NORM: }(0.00,0.00,0.00)\end{array}$ & $\begin{array}{l}\text { FT NAME: top_pock } \\
\text { FT CLASS: pocket } \\
\text { SUB-TYPE: porec } \\
\text { OF COMP_FT: na } \\
\text { DIM1: } 70.00 \\
\text { DIM2: } 80.00 \\
\text { DEPTH: } 10.00 \\
\text { RADIUS: } 0.00 \\
\text { SURF FINISH: } 0.05 \\
\text { LOC: }(0.00,0.00,40.00) \\
\text { X: }(1.00,0.00,0.00) \\
\text { Y: }(0.00,1.00,0.00) \\
\text { Z: (0.00,0.00,1.00) } \\
\text { FACE: top_pock.11.im } \\
\text { TYPE: i } \\
\text { PARENT: blk.11.bl } \\
\text { NORM: }(0.00,0.00,1.00) \\
\text { FACE: top_pock.t2.re } \\
\text { TYPE: } r \\
\text { PARENT: } \\
\text { NORM: }(0.00,0.00,-1.00) \\
\text { FACE: top_pock. }\{3 . r e \\
\text { TYPE: } r \\
\text { PARENT: } \\
\text { NORM: }(1.00,0.00,0.00) \\
\text { FACE: top_pock. } 44 . r e \\
\text { TYPE: } r \\
\text { PARENT: } \\
\text { NORM: }(0.00,-1.00,0.00) \\
\text { FACE: top_pock. } 15 . r e \\
\text { TYPE: } r \\
\text { PARENT: } \\
\text { NORM: }(-1.00,0.00,0.00) \\
\text { FACE: top_pock. } f 6 . r e \\
\text { TYPE: } r \\
\text { PARENT: } \\
\text { NORM: }(0.00,1.00,0.00) \\
\end{array}$ & $\begin{array}{l}\text { FT NAME: bot_hole } \\
\text { FT CLASS: hole } \\
\text { SUB-TYPE: hoobr } \\
\text { OF COMP_FT: na } \\
\text { DIM1: } 8.00 \\
\text { DIM2: } 0.00 \\
\text { DEPTH: } 30.00 \\
\text { RADIUS: } 8.00 \\
\text { SURF FINISH: } 0.01 \\
\text { LOC: }(0.00,0.00,30.00) \\
\text { X: }(1.00,0.00,0.00) \\
\text { Y: }(0.00,1.00,0.00) \\
\text { Z: (0.00,0.00,1.00) } \\
\text { FACE: bot_hole.11.im } \\
\text { TYPE: i } \\
\text { PARENT: top_pock.f2.re } \\
\text { NORM: }(0.00,0.00,1.00) \\
\text { FACE: bot_hole.f2.im } \\
\text { TYPE: i } \\
\text { PARENT: blk.t2.bl } \\
\text { NORM: }(0.00,0.00,-1.00) \\
\text { FACE: bot_hole. }\{3 . r e \\
\text { TYPE: } r \\
\text { PARENT: } \\
\text { NORM: }(0.00,0.00,0.00) \\
\text { FACE: bot_hole. }\{4 . r e \\
\text { TYPE: r } r \\
\text { PARENT: } \\
\text { NORM: }(0.00,-1.00,0.00) \\
\text { FACE: bot_hole.f5.re } \\
\text { TYPE: } r \\
\text { PARENT: } \\
\text { NORM: }(0.00,0.00,0.00) \\
\text { FACE: bot_hole.f6.re } \\
\text { TYPE: r } \\
\text { PARENT: } \\
\text { NORM: }(0.00,1.00,0.00) \\
\end{array}$ \\
\hline
\end{tabular}

\section{References}

Butterfield, W. R., Green, M. K., Scott, D. C., Stocker, W. J., "Part features for process planning", CAM-I C-85-PPP-Q3, 1985.

Case, K. and Gao, J. X., "Feature technology: an overview", International Journal of Computer Integrated Manufacture, January 1993.

Dixon, J. R., "Design with features: building manufacturing knowledge into more intelligent CAD systems", ASME Manufacturing International'88, Atlanta, GA, USA. 1988

Gao, J. X. and Case, K., "A design by features approach to the building of feature data models for process planning", Computer Aided Production Engineering (CAPE) 8, University of Edinburgh, August 1992.

Gao, J. X. and Case, K., "Specification of feature based component data model", research report to the Science and Engineering Research Council (SERC), directorate of Application of
Computers in Manufacturing Engineering (ACME), grant no. GR/G35657, June 1991.

Gindy, N. N. Z. and Huang, S. X., "Feature based planning data model for generative planning systems", MATADOR'92, UMIST, Manchester, April 1992.

Gindy, N. N. Z., "A hierarchical structure for form features", International Journal of Production Research, Volume 27, Number 12, 1989.

Pafec Limited, "Horses kernel User Manual", Pafec Limited, Nottingham, UK, 1991.

Shah, J. J., Bhatnagar, A. and Hsiao, D., "feature mapping and application shell", Computer Aided Engineering, 1988.

Shah, J. J. and Rogers, M. T., "Feature based modelling shell: design and implementation", Computers in Engineering, January 1990. 